\title{
Effect of probiotic fermented dairy products on incidence of respiratory tract infections: a systematic review and meta- analysis of randomized clinical trials
}

\author{
Kamil Rashidi ${ }^{1}$, Bahman Razi ${ }^{2}$, Mina Darand ${ }^{3}$, Azadeh Dehghani ${ }^{4,5}$, Parisa Janmohammadi ${ }^{6}$ and Shahab Alizadeh ${ }^{6 *}$
}

\begin{abstract}
Background: Previous studies have suggested that the consumption of probiotic fermented dairy products (PFDP) may have a protective effect on respiratory tract infections (RTIs). However, the results of studies are inconclusive. We aimed to systematically investigate the effect of PFDP on RTls by performing a meta-analysis of randomized controlled trials (RCTs).

Methods: PubMed and Scopus databases were systematically searched up to October 2020 to identify eligible RCTs. Meta-analysis outcomes were risk of incidence of upper (URTIs) and lower (LRTIs) respiratory tract infections. A random-effects model was used to pool the relative risks (RR) and corresponding $95 \%$ confidence intervals (CI) for outcomes following conception of PFDP.

Results: A total of 22 RCTs, with a total sample size of 10,190 participants, were included in this meta-analysis. Compared with placebo, consumption of PFDP had a significant protective effect against RTIs in the overall analysis $(R R=0.81,95 \% \mathrm{Cl}: 0.74$ to 0.89 ) and in children ( $R R=0.82,95 \% \mathrm{Cl}: 0.73$ to 0.93 ), adults (RR $=0.81,95 \% \mathrm{Cl}: 0.66$ to 1.00), and elderly population ( $\mathrm{RR}=0.78,95 \% \mathrm{Cl}: 0.61$ to 0.98$)$. The significant decreased risk of RTIs was also observed for URTIS (RR $=0.83,95 \% \mathrm{Cl}: 0.73$ to 0.93 ), while, this effect was marginal for LRTIs (RR $=0.78,95 \% \mathrm{Cl}: 0.60$ to $1.01, P=0.06$ ). The disease-specific analysis showed that PFDP have a protective effect on pneumonia ( $R R=0.76$, $95 \% \mathrm{Cl}: 0.61$ to 0.95$)$ and common cold (RR $=0.68,95 \% \mathrm{Cl}: 0.49$ to 0.96$)$.
\end{abstract}

Conclusions: Consumption of PFDP is a potential dietary approach for the prevention of RTIs.

Keywords: Probiotics: Fermented milk, Fermented dairy products, Respiratory tract infections, Meta-analysis

\section{Research highlights}

- Consumption of PFDP had a significant protective effect against RTIs in all age groups.

- PFDP had a protective effect on pneumonia and common cold.

* Correspondence: sh_alizadeh@razi.tums.ac.ir

${ }^{6}$ Department of Clinical Nutrition, School of Nutritional Sciences and Dietetics, Tehran University of Medical Sciences (TUMS), Tehran, Iran Full list of author information is available at the end of the article
- The protective effect of PFDP was modified by probiotic genus and type of dairy product used for intervention.

\section{Background}

Acute respiratory infections (RTI, including upper RTI (URTI), e.g., cold, and lower RTI (LRTI), e.g., pneumonia and bronchitis, are a pervasive public health problem in all developed and developing countries, leading to nearly four million deaths annually, with more than 60

(c) The Author(s). 2021 Open Access This article is licensed under a Creative Commons Attribution 4.0 International License, which permits use, sharing, adaptation, distribution and reproduction in any medium or format, as long as you give appropriate credit to the original author(s) and the source, provide a link to the Creative Commons licence, and indicate if changes were made. The images or other third party material in this article are included in the article's Creative Commons licence, unless indicated otherwise in a credit line to the material. If material is not included in the article's Creative Commons licence and your intended use is not permitted by statutory regulation or exceeds the permitted use, you will need to obtain permission directly from the copyright holder. To view a copy of this licence, visit http://creativecommons.org/licenses/by/4.0/. The Creative Commons Public Domain Dedication waiver (http://creativecommons.org/publicdomain/zero/1.0/) applies to the data made available in this article, unless otherwise stated in a credit line to the data. 
deaths per 100,000 population [1]. ARIs are a main public health problem worldwide and contribute to increased morbidity and mortality, as they result in a large number of outpatient visits, hospital admissions, and the widespread administration of antibiotics [2]. These diseases affect all age groups every year and put a heavy burden on the world's health and economic systems. More than 200 types of viruses have been identified as causing respiratory diseases [3,4]. As well as, $90 \%$ of deaths because of respiratory infections are reported to happen in patients over 65 years of age [5]. Young children are more likely to get this respiratory infection than adults or children $[6,7]$. In most cases, the diseases of the upper respiratory tract are mild to moderate and mostly self-limiting. However, LRTIs-induced pneumonia can be predominantly fatal in children and the elderly or in immunocompromised individuals $[4,8]$.

The health benefits of fermented milk and dairy products have long been known. The health benefits of dairy products are the consequence of the biologically active ingredients existing in native milk and are also produced in fermented or sour milk products produced by the action of probiotic bacteria [9]. Probiotics have been used as an adjunct to reduce the risks of widespread use of antibiotics such as diarrhea and to prevent infections, including respiratory infections [10]. One reason that probiotics are considered to be the main and important components of the diet to reduce the risk of infectious diseases is due to their functional role in the gastrointestinal tract and intestinal epithelium, as well as their relationship with the function of the immune system and intestinal mucosa $[11,12]$. Probiotics are living microorganisms that, if administered in sufficient doses, provide health benefits to the host [13].

Studies show that functional foods from fermented cow's milk with probiotic strains can well prevent infectious diseases, but the data are still inconsistent [14-19]. Prevention or control of infectious diseases is one of the most promising health benefits of probiotics [20-22]. The useful effects of lactic acid bacteria and cultured milk products have been ascribed to their capability to suppress the growth of pathogens instantly or via the genesis of antibacterial agents [23]. The results of several studies have shown that some probiotics are effective against infections of the gastrointestinal tract and respiratory tract [24]. Furthermore, it has been demonstrated that probiotics have an essential role in extenuating the rate of ARI episodes and antibiotic use [25]. Nonetheless, there are little well-designed individual interventional studies, with contradictory findings, assessing the clinical effects of dairy, mostly for yogurt and milk, supplemented with chosen probiotics against acute RTI.
Considering the potential of probiotic products and the importance of medical nutrition therapy of respiratory tract infections, the current meta-analysis of recently conducted randomized controlled trials (RCTs) aimed to assess the effect of fermented dairy products by probiotics on incidence of respiratory tract infections in children, adults, and elderly.

\section{Main text \\ Methods \\ Search strategy}

We followed PRISMA guidelines (Preferred Reporting Items for Systematic Reviews and Meta-Analyses) in the design and reporting of the methods for this systematic review [1]. PubMed and Scopus online databases were searched from inception to October 2020 for RCTs examining the effect of probiotic fermented dairy products on incidence of respiratory tract infections. A different combination of keywords was searched (Supplemental file 1). Where possible, Medical Subject Headings in addition to free-text search terms were used in the search. The search results were limited to English-language publications. In addition, we checked references of retrieved eligible papers and previous review articles in this area to make sure we found all relevant articles.

\section{Screening and study selection}

First, electronic and manual search results were exported to EndNote software, version X8 (Thomson Reuters) and duplicate publications were eliminated. Selection of eligible controlled trials was carried out independently by two investigators (SA \& PJ). Any discrepancies were resolved by consensus. The researchers first assessed the titles and abstracts of studies obtained through preliminary searches, then, independently reviewed the full text of remaining publications.

\section{Eligibility criteria}

The PICO for this Meta-analysis and systematic review include: P: People diagnosed with an acute RTI, I: Consuming probiotic fermented dairy products (PFDP), C: Not consuming PFDP, O: Risk of incidence of URTIs or LRTIs. Also, articles were included for analysis if they conformed to the following criteria: (1) were RCT in design; (2) provided original data on the effect of probiotic fermented dairy products on incidence of respiratory tract infections; (3) were published in English; (4) done on human subjects; (5) had full text available, and (6) provided a comparison group. Trials that did not meet our inclusion criteria were excluded, and the remaining studies were selected for further analysis. 


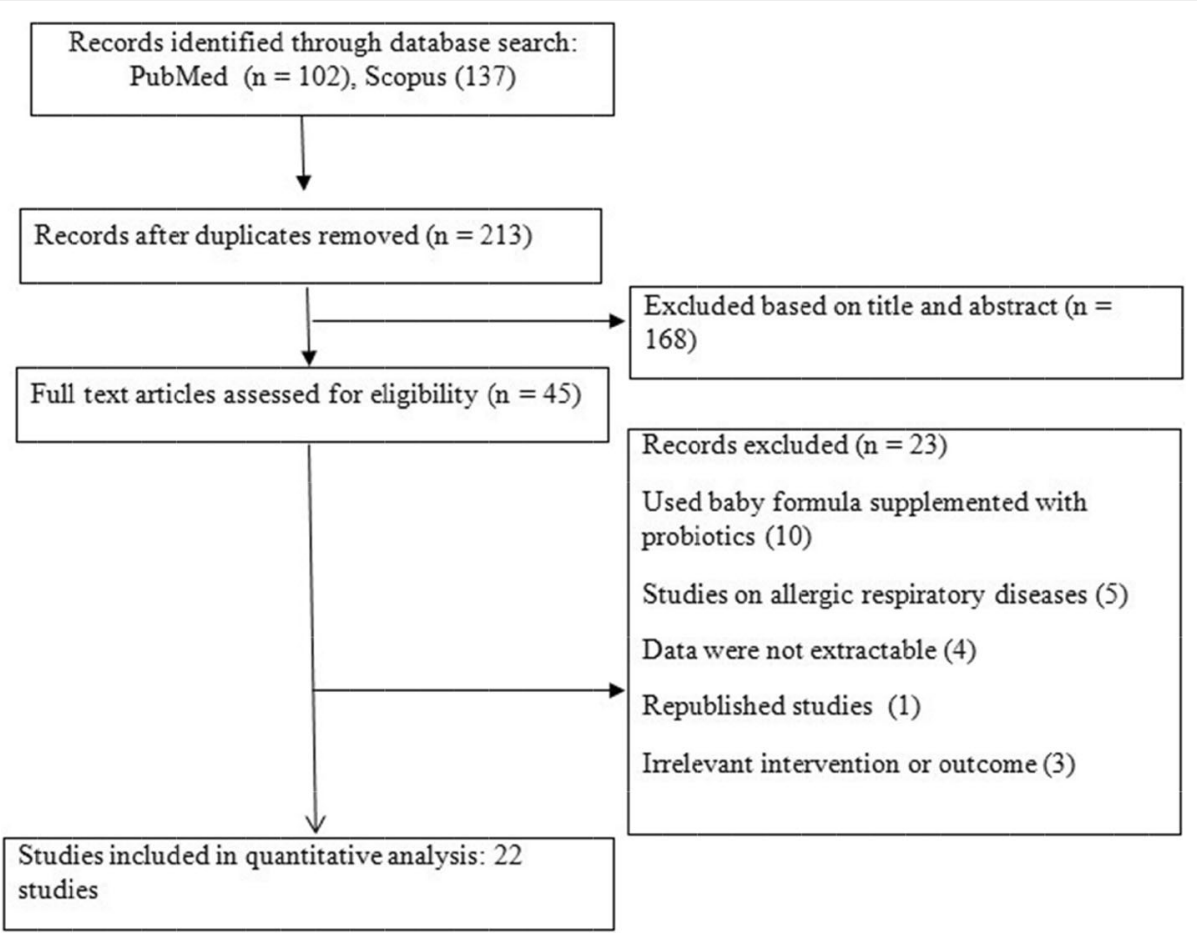

Fig. 1 Flow diagram of the study

\section{Data extraction}

Data extraction was performed by two investigators, independently (SA and PJ) using a standardized data extraction sheet. Subsequently, full texts studies were assessed, and disagreements were resolved through discussion with a third independent researcher (BR). The following information was extracted: first author's name, publication year, country/geographic location, study design including whether parallel or cross-over, target population, mean age, gender, number of participants, study duration, type and dosage of PFDP, relative risks (RR) and $95 \%$ confidence interval (CI) of RTIs.

\section{Quality assessment of studies}

Two reviewers (MD \& AD) independently assessed the quality of each study according to the Cochrane risk of bias [2], which is composed of the following criteria: random sequence generation, allocation concealment, blinding, and clarification of failures (imperfect outcome data), selective outcome reporting and other biases. According to the Cochrane guideline handbook, the words "yes," "no," and "unclear" corresponded to low, high, and unknown risk of bias, respectively. According to the mentioned domains, the overall quality of study was considered as good (low risk for all items), fair (low risk more than three items), and poor (low risk for 3 or fewer items).

\section{Data synthesis and analysis}

All analyses were performed using STATA software version 12 (STATA corp, College Station, TX, USA). Due to the fact that selected RCTs were carried out in different settings, a random-effects model was used to pool the RR and $95 \% \mathrm{CI}$ for outcomes following consumption of PFDP. Heterogeneity was examined using the Isquared $\left(I^{2}\right)$ index. An $I^{2}$ value $>50 \%$ was considered to indicate substantial heterogeneity between trials [4]. To explore the source of heterogeneity, in addition to the general analysis, we performed subgroup analyses by studied population, probiotic genus used in dairy products, type of dairy product, and type of RTI. Metaregression analysis was also carried out to explore the effect of the duration of supplementation and age of participants of pooled estimates. The presence of publication bias was tested using the Egger's regression asymmetry test and $P<0.05$ was considered statistically significant, except where otherwise specified.

\section{Results}

\section{Study characteristics}

A total of 239 articles were identified through the systematic literature search of databases. After excluding 26 duplicate studies and removing 168 irrelevant publications based on titles/abstracts, 45 studies went under full-text screening. Of which, 23 paper were excluded based on the inclusion criteria because they used baby formula supplemented with probiotics as intervention, 


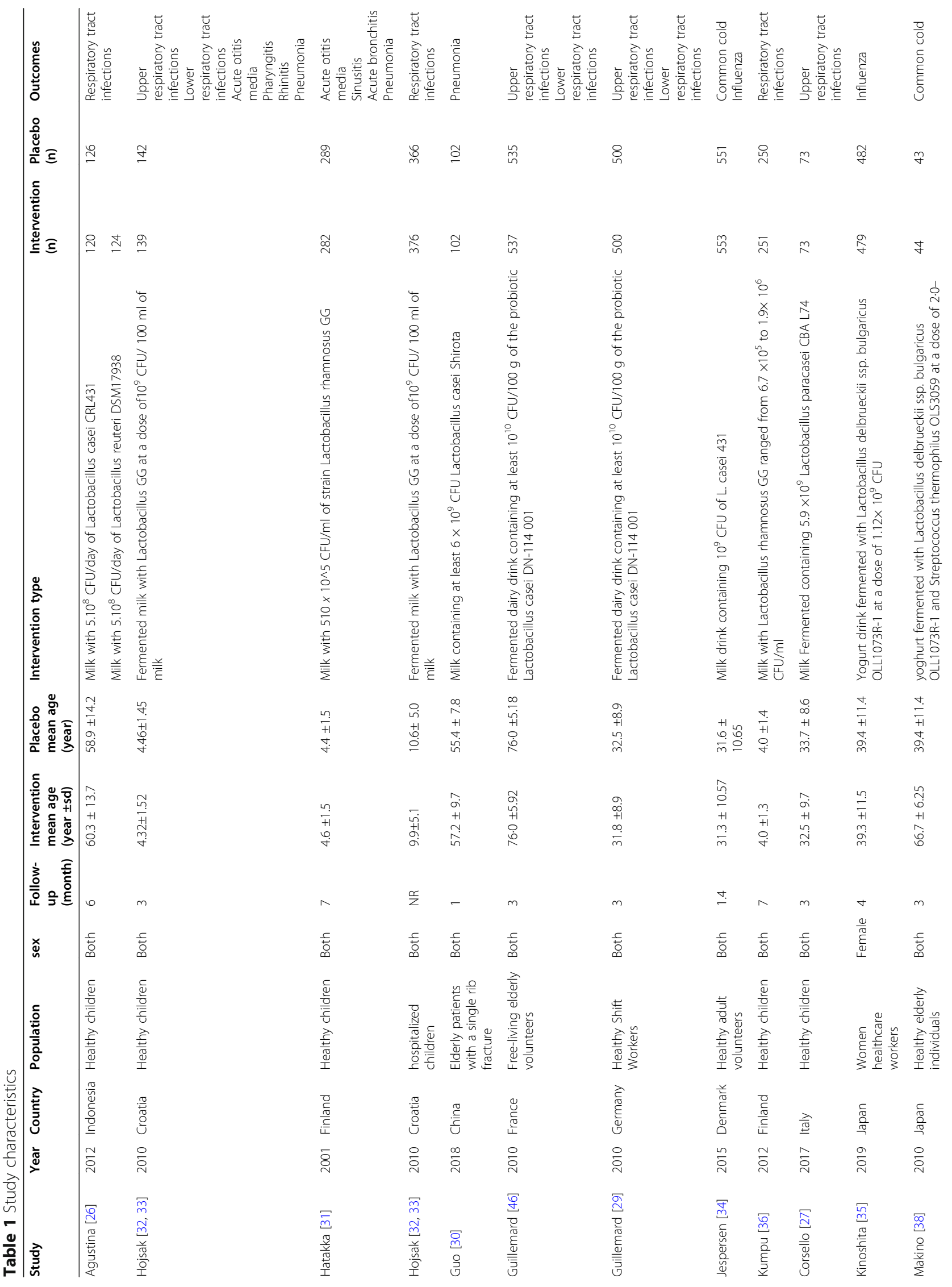




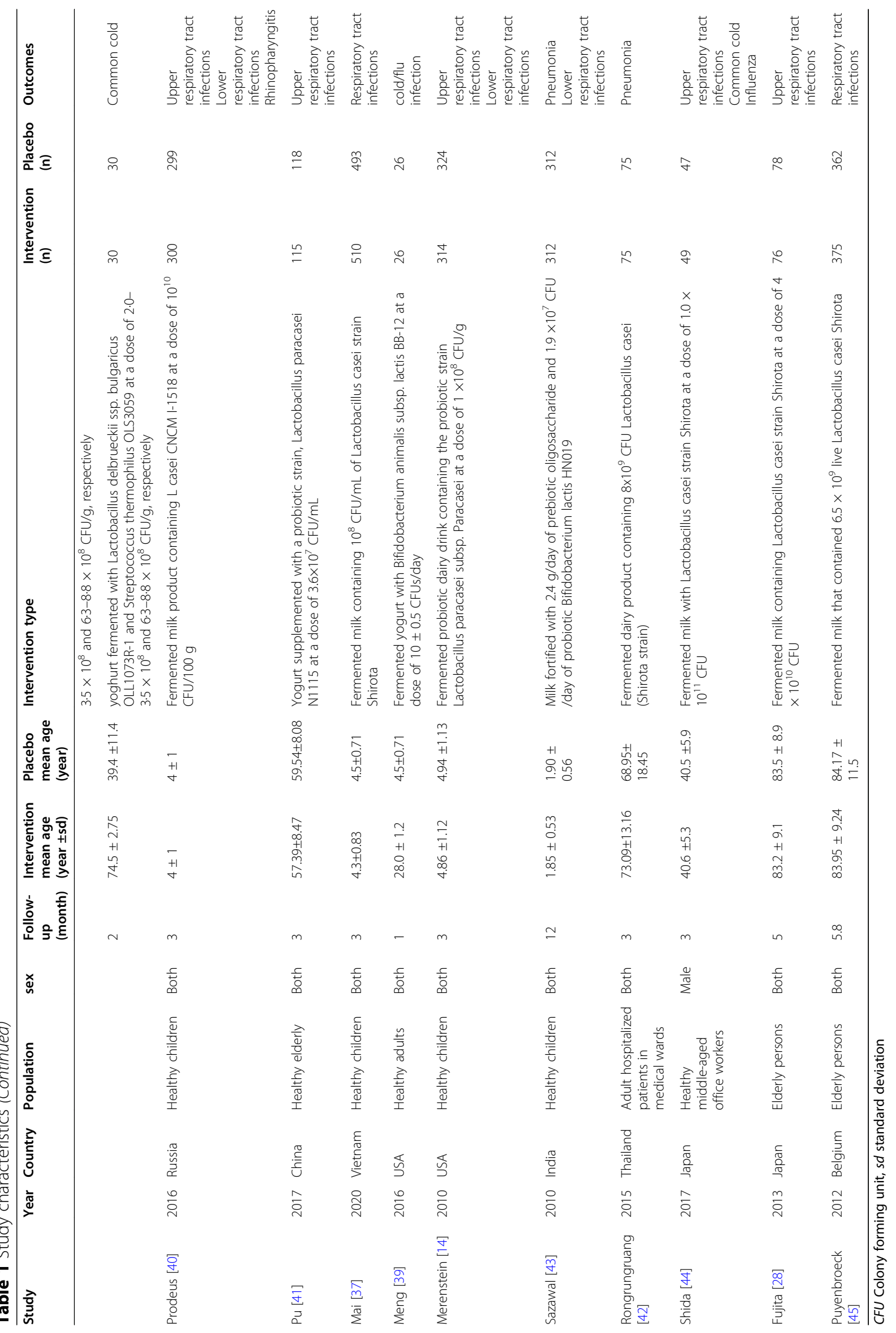




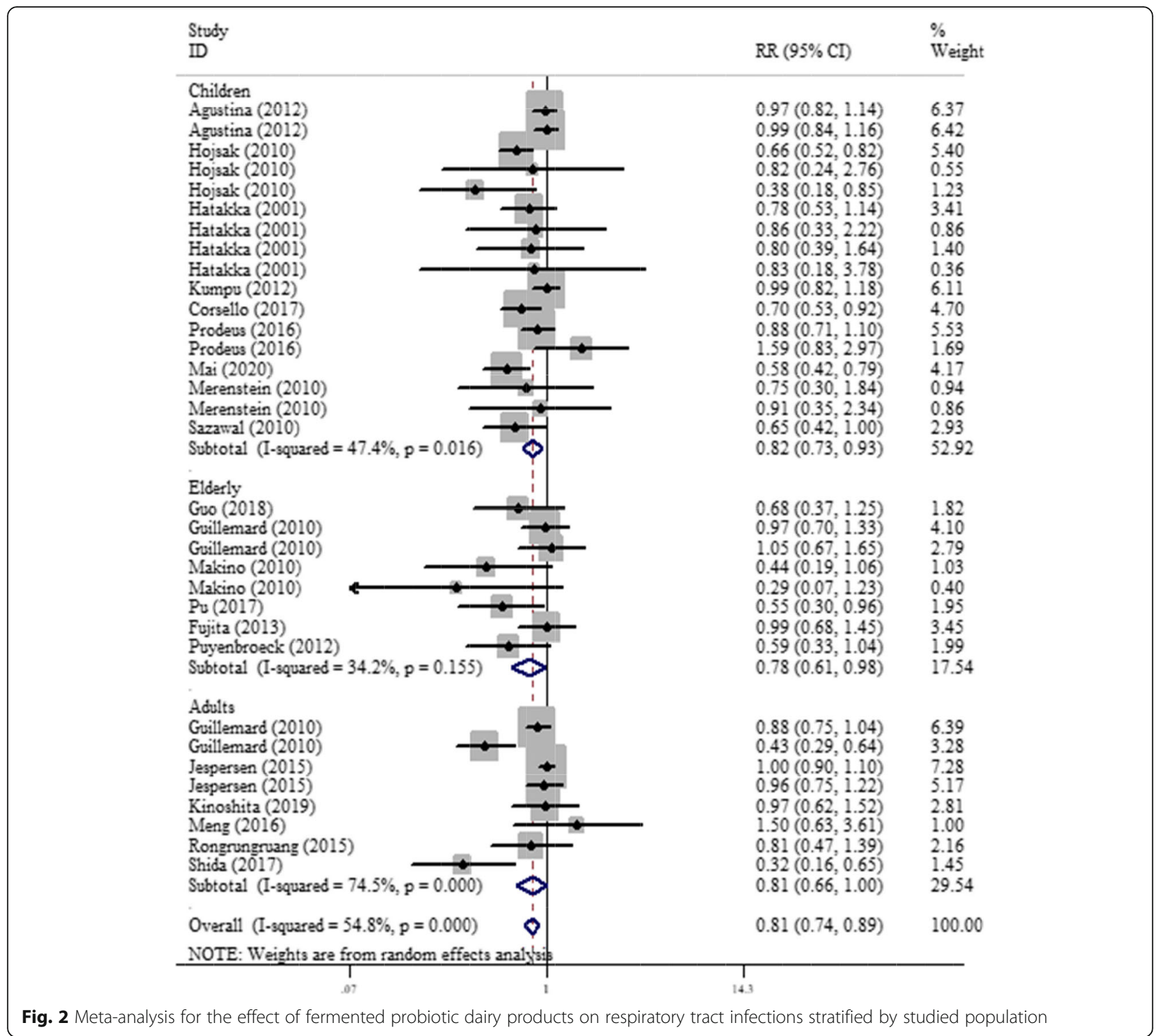

were on allergic respiratory diseases, were republished studies, did not report sufficient extractable data, or had irrelevant intervention or outcome. Finally, 22 clinical trials with 33 datasets [14, 26-46], with a total sample size of 10,190 subjects were included in this metaanalysis. The flow diagram of study selection is presented in Fig. 1. Some studies reported multiple results; we extracted all suitable data for such studies. For instance, the study by Agustina et al. [26] contained two interventions, a group received fermented milk with Lactobacillus casei CRL431 and another group received fermented milk with Lactobacillus reuteri DSM17938, which both were included. The study by Makino et al. [38] included two separate studies and both were eligible for our meta-analysis. Moreover, some studies reported results for different respiratory tract infections (RTIs) separately, which all effect sizes were included. Data on total RTIs, lower respiratory tract infections (LRTIs), and upper respiratory tract infections (URTIs) were reported in 5 studies with 6 data sets [26, 33, 36, 37, 45], 9 studies with 10 data sets $[14,29-32,40,42,43,46]$, and 14 studies with 17 data sets $[14,27-29,31,32,34,35$, $38-41,44,46]$, respectively. Among the included studies, there were 10 studies with 17 data sets on children [14, $26,27,31-33,36,37,40,43]$ and 6 studies with 8 data sets for each adult $[29,34,35,39,42,44]$, and elderly population $[28,30,38,41,45,46]$. The probiotic genus used in fermented dairy products was Lactobacillus in 20 studies [14, 26-38, 40-42, 44-46] and Bifidobacterium in 2 studies $[39,43]$. Furthermore, the fermented dairy products used as intervention was milk in 14 studies with 21 data sets [26-28, 30-34, 36, 37, 40, 43-45], 
Table 2 Subgroup analyses for the effect of probiotic dairy products on respiratory tract infections

\begin{tabular}{|c|c|c|c|c|c|c|}
\hline Subgrouped by & No. of data sets & $\operatorname{RR}^{\mathrm{a}}(95 \% \mathrm{Cl})$ & $P$ value $^{\mathrm{b}}$ & $12(\%)^{c}$ & & $P$ value \\
\hline Overall & 33 & $0.81(0.74$ to 0.89$)$ & $<0.001$ & 54.8 & $<0.001$ & \\
\hline \multicolumn{7}{|l|}{ Population type } \\
\hline Children & 17 & $0.82(0.73$ to 0.93$)$ & 0.001 & 47.4 & 0.01 & \\
\hline adults & 8 & $0.81(0.66$ to 1.00$)$ & 0.04 & 41.8 & 0.07 & \\
\hline Elderly & 8 & $0.78(0.61$ to 0.98$)$ & 0.03 & 34.2 & 0.15 & \\
\hline \multicolumn{7}{|l|}{ Probiotic genus } \\
\hline Lactobacillus & 31 & 0.81 (0.74 to 0.90$)$ & $<0.001$ & 55.6 & $<0.001$ & \\
\hline Bifidobacterium & 2 & $0.90(0.41$ to 2.01$)$ & 0.80 & 64.6 & 0.09 & \\
\hline \multicolumn{7}{|l|}{ Dairy type } \\
\hline Milk & 21 & $0.83(0.74$ to 0.92$)$ & $<0.001$ & 58.0 & $<0.001$ & \\
\hline Dairy drink & 7 & $0.80(0.64$ to 1.02$)$ & 0.07 & 54.3 & 0.04 & \\
\hline Yoghurt & 5 & $0.71(0.44$ to 1.13$)$ & 0.15 & 49.6 & 0.09 & \\
\hline \multicolumn{7}{|l|}{ Type of infection } \\
\hline RTIS & 6 & $0.82(0.67$ to 1.00$)$ & 0.05 & 71.1 & 0.004 & \\
\hline URTIS & $` 17$ & 0.83 (0.73 to 0.93 ) & 0.002 & 52.3 & 0.006 & \\
\hline LRTIS & 10 & $0.78(0.60$ to 1.01$)$ & 0.06 & 43.3 & 0.07 & \\
\hline
\end{tabular}

RTIs Respiratory tract infections, URT/s Upper respiratory tract infections, LRTIs Lower respiratory tract infections, RR relative risk

${ }^{a}$ Effect size was expressed as relative risk and $95 \%$ confidence interval

${ }^{b}$ For meta-analysis: $P \leq 0.05$ was considered to be a significant effect by using a random-effects model

'The $\mathrm{I}^{2}$ statistic was calculated by using Cochran's test, and $\mathrm{I}^{2}$ statistic $>50 \%$ was considered to indicate significant heterogeneity across studies

${ }^{\mathrm{d}} \mathrm{P}$ value for 12

yogurt in 4 studies with 5 data sets [35, 38, 39, 41], and a dairy drink in 4 studies with 7 data sets $[14,29,42$, 46]. Concerning study design, all studies were parallel RCT, except for the study by Meng et al.[39], which had a crossover design. The sample size of the included studies ranged from 52 to 1104 participants and follow-up period was between 1 and 12 months. Based on the Cochrane scale, all included studies received scored as moderated to high quality. Other characteristics of the analyzed publications are reported in Table 1.

\section{Quantitative analysis}

Overall and stratified analysis by studied population for the effect of probiotic fermented dairy products (PFDP) on RTIs is presented in Fig. 2. When all studies were pooled, it was found that, compared with placebo, consumption of PFDP has a significant protective effect against RTIs in the overall analysis $(R R=0.81$, $95 \% \mathrm{CI}: 0.74$ to 0.89$)$ and in children $(\mathrm{RR}=0.82$, $95 \% \mathrm{CI}: 0.73$ to 0.93 ), adults ( $\mathrm{RR}=0.81,95 \% \mathrm{CI}: 0.66$ to 1.00$)$, and elderly population ( $\mathrm{RR}=0.78,95 \% \mathrm{CI}$ : 0.61 to 0.98 ), with a significant heterogeneity across studies $(\mathrm{I} 2=54.8 \%, P<0.001)$. The significant decreased risk of RTIs was also observed for URTIs $(\mathrm{RR}=0.83,95 \% \mathrm{CI}: 0.73$ to 0.93$)$, while, this association was marginal for LRTIs $(\mathrm{RR}=0.78,95 \% \mathrm{CI}$ : 0.60 to $1.01, P=0.06$ ). In the subgroup analysis, the significant impact of PFDP on RTIs was modified by probiotic genus and type of dairy product used for intervention; while, PFDP consumption had a protective effect on RTIs when Lactobacillus and milk were used as probiotic and fermented dairy product, respectively, but no significant effect was found in studies which administered Bifidobacterium and dairy drink or yogurt (Table 2).

\section{Fermented probiotic dairy products and specific respiratory tract infections}

Meta-analysis for the effect of PFDP on specific respiratory tract infections showed that the consumption of PFDP has a protective effect on pneumonia $(R R=0.76$, $95 \% \mathrm{CI}: 0.61$ to 0.95$)$ and common cold $(\mathrm{RR}=0.68$, 95 \%CI: 0.49 to 0.96$)$. PFDP had no significant effect on other RTIs (Fig. 3).

\section{Meta-regression, sensitivity analysis, and publication bias} Meta-regression analysis showed that the effect of PFDP on RTIs was not modified by the duration of supplementation and age of participants (Fig. 4). There was a significant evidence for possible publication bias based on funnel plots asymmetry and Egger's linear regression test $(\mathrm{t}=-3.02, P=0.005)$ (Fig. 5$)$. In the sensitivity analysis by removing one study at a time and reanalyzing 


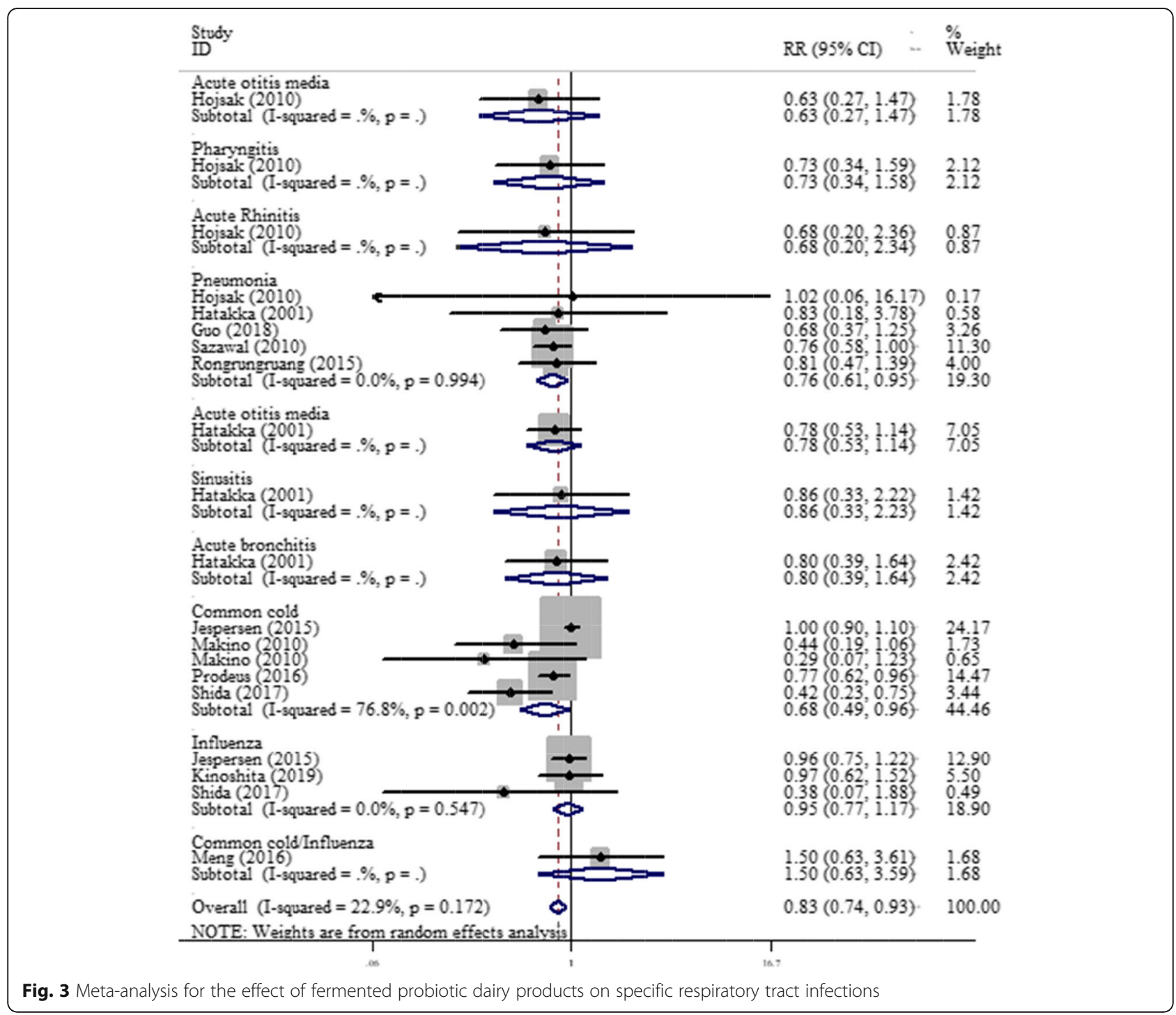

other studies, the polled effect size ranged from $(\mathrm{RR}=$ $0.79,95 \% \mathrm{CI}: 0.72$ to 0.88 ) to ( $\mathrm{RR}=0.83,95 \% \mathrm{CI}: 0.76$ to 0.91 ) and no single study significantly affected the pooled effect estimate, showing the reliability of the findings.

\section{Discussion}

During the past years, numerous investigations have evaluated the potential role of fermented probiotic dairy products against RTIs. Notwithstanding, these studies yielded inconclusive findings. Differences in the experimental design, lower sample sizes, and bacterial strains used in the preparation of the fermented products might be the underlying cause of such conflicting results. To resolve the problem of inconsistency by abrogating the limiting issues present in the individual studies we conducted the current meta-analysis which is the most up-to-date study that contained a significantly higher frequency of studies and individuals in the intervention/ placebo groups, and indicated beneficial effects of FPDPs supplementation in reducing the risk of RTIs. Accordingly, overall and stratified analysis highlighted decreased risk of RTIs in overall population, all age subgroup, dairy products fermented with Lactobacillus and those who consume fermented probiotic milk, but not diary drink and yogurt.

Probiotics are defined as "beneficial live microorganisms which its administration in optimal amount confer a health benefit to the user". The boosting effects of probiotics on the function of gastrointestinal and respiratory systems have been proposed by several studies performed on humans and animals [47, 48]. However, the observed beneficial effects are bacterial strain dependent. It is highlighted that lactobacillus casei resistant to 


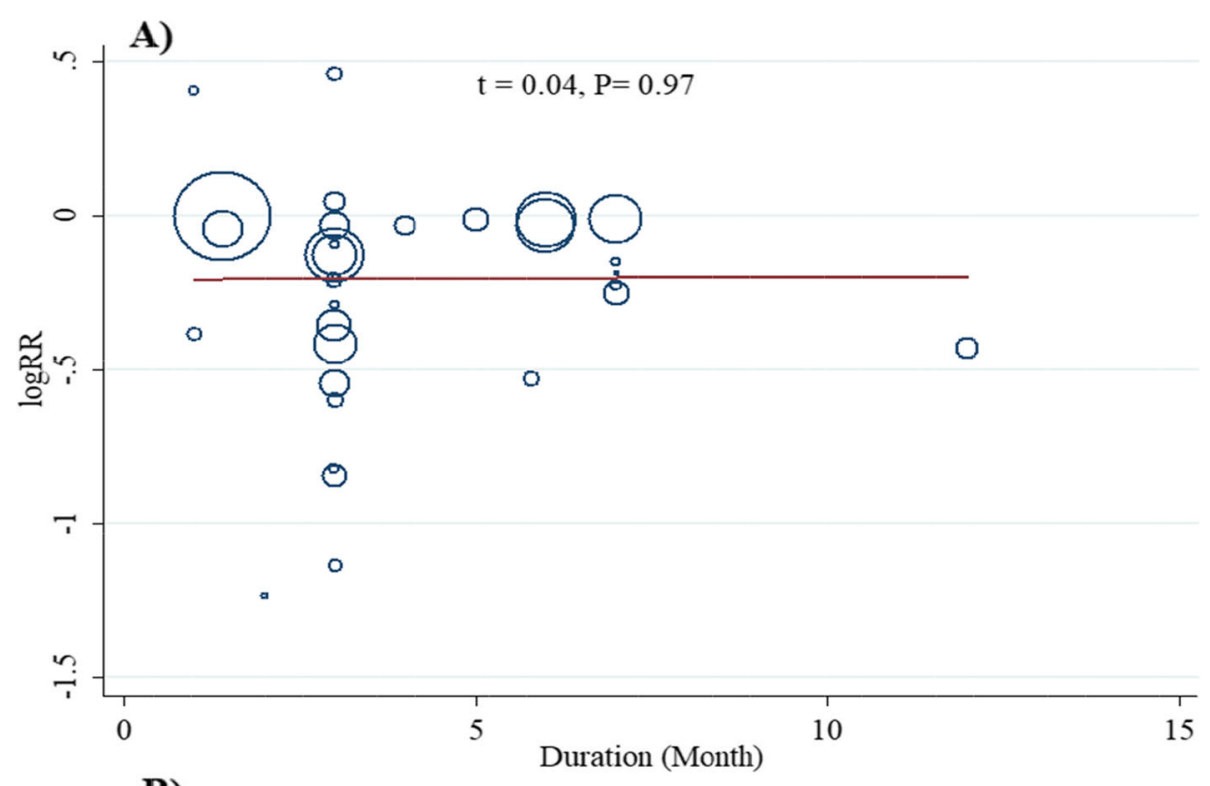

B)

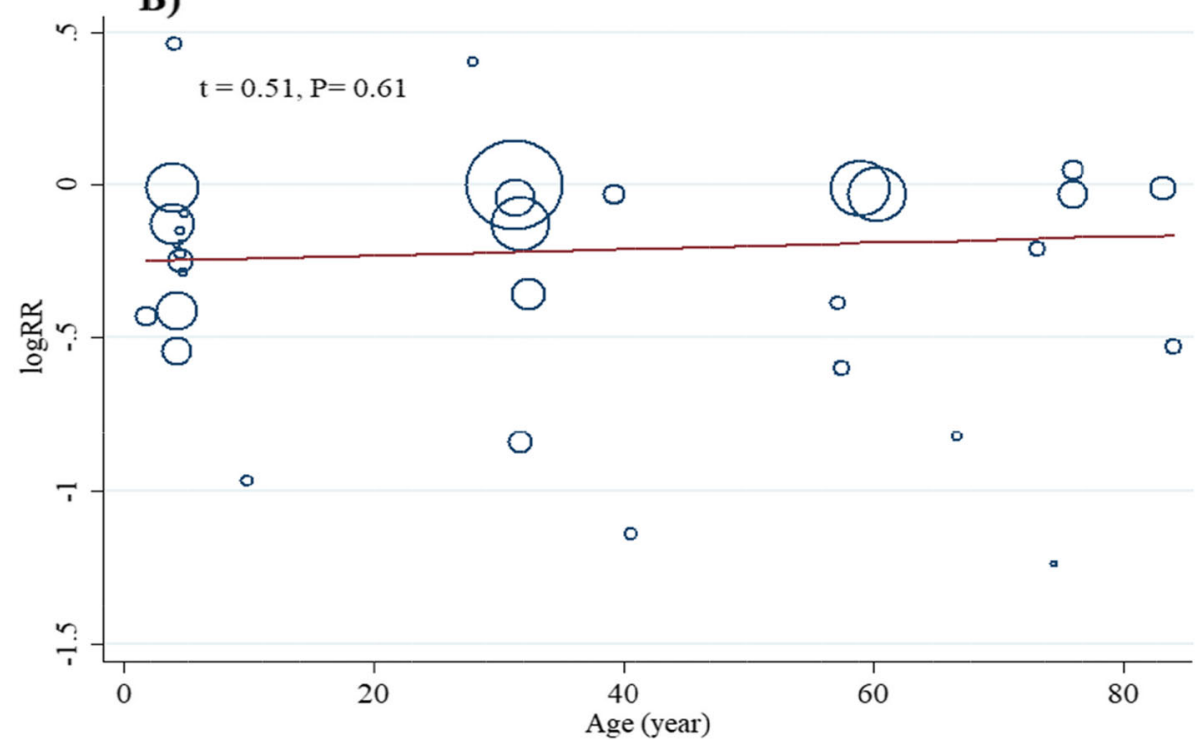

Fig. 4 Meta-regression analysis for the effect of fermented probiotic dairy products on respiratory tract infections based on follow-up duration (A) and age of participants (B)

gastric acid and bile. In this regard, several studies have shown that lactobacillus-containing products reach the lower digestive tract without losing its activity, and after localization balance the intestinal flora by promotion of immune cells that are produced in the lower intestinal tract. These cells might migrate to other mucosal sites and contribute in protection against pathogens [49-51].

So far, several mechanisms have been suggested on the effectiveness of probiotics to promote immune system. Firstly, Lactobacillus cause an anti-inflammatory impact by reduction of Interleukin-12 (IL-12) and stimulation of Interleukin-10 (IL-10) [52]. From immunological point of view, IL-10 derived from CD4 + T-helper type 2 . This cytokine identified as potent inhibitor of monocyte/ macrophage function and suppress the production of many pro-inflammatory cytokines [53]. Secondly, probiotics present an immunostimulatory effect which resulted in activation of innate and acquired immunity cells and subsequently production of innate and acquired immunity peptides. Paneth cells, neutrophils, and epithelial cells are among activated cells which produce antimicrobial peptides (AMPs) like lysozyme, lactoferrin, defensins and defend the body against pathogens [54, 55]. Moreover, secretory immunoglobulin A (IgA) which is a functional acquired immunity peptides defenses against pathogens either by immune exclusion or 
Funnel plot with pseudo $95 \%$ confidence limits

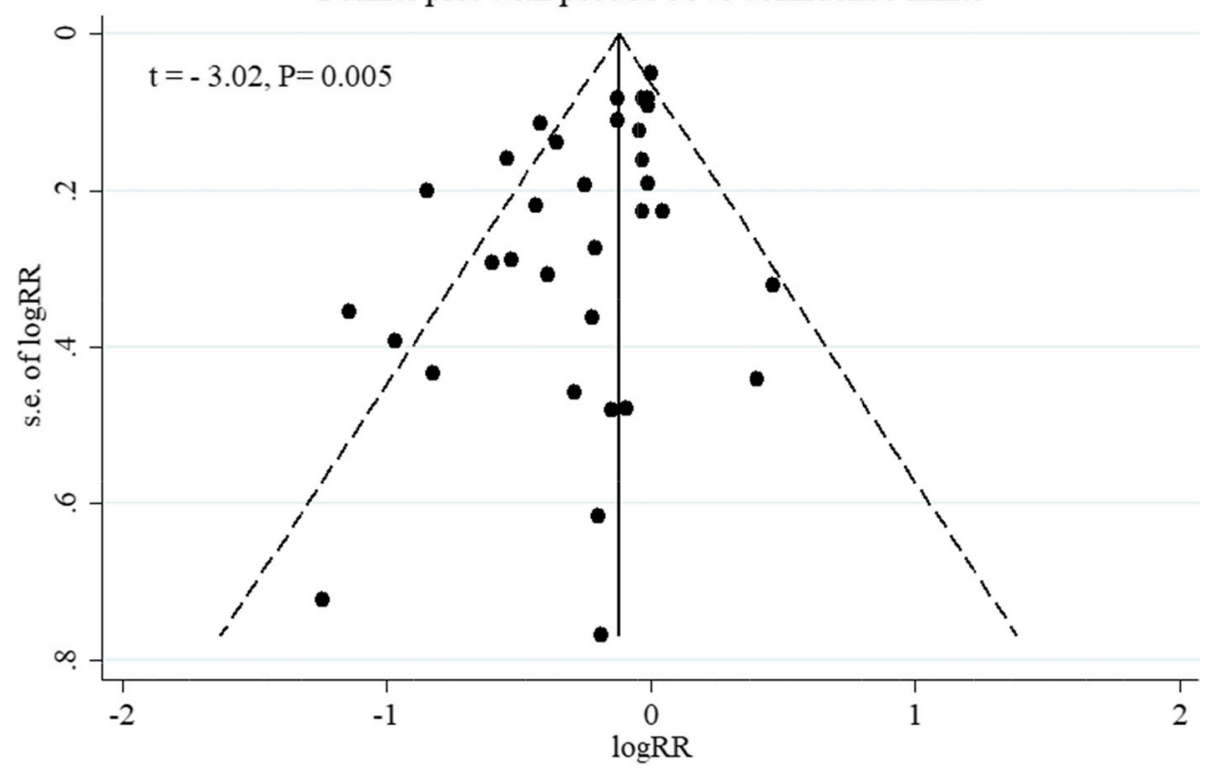

Fig. 5 Funnel plot for publication bias in studies investigating the effect of fermented probiotic dairy products on respiratory tract infections

neutralization mechanism [56]. Studies have shown that probiotics induce AMPs, IgA, and IgG, resulting in an augmentation of immune system against infections $[57,58]$. In confirm of the aforementioned theoretical facts, Reale et al. showed that probiotic intake can restore natural killer (NK) cell activity, member of innate immunity cells, which strengthen the host's immune defense and induce a quick recovery by shortening the duration of infection $[59,60]$. As our results show, consumption of FPDPs significantly decreased risk of RTIs in all age groups which can be a promising finding supported by potential biological mechanisms. Reduction of RTIs by FPDPs is highly important is it is accompanied by a reduction in medication use, working and school days loss, and social burden. It should be considered that the nonsignificant effect of studies which administered Bifidobacterium and dairy drink or yogurt on RTIs is due to small number of analyzed studies in these subgroups, which is important to be interpreted with a high caution.

Our meta-analysis was not bereft of limitations and caveats. First, we searched only English-written papers, which may raise the possibility of omission of potentially valuable studies and cause publication bias. Second, we observed a significant heterogeneity among the studies that might stem largely from, ethnicity of participants, year of publication, age, clinical heterogeneity, unreported and unknown study characteristics and many other factors which we are not able to attenuate their impact on final analysis.
Therefore, for finding any sources of heterogeneity and attenuating their effects, we conducted subgroup analysis and weighted meta-regression. Collectively, the results of meta-regression showed that duration of supplementation and age of participants were not the expected source of heterogeneity, but probiotic genus and type of dairy product used for intervention were found as sources of observed heterogeneity. However, to deal with statistical heterogeneity, a random-effects model was applied for analyzes, which typically produces more conservative estimates of the significance of a result (a wider confidence interval), as it gives proportionately higher weights to smaller studies and lower weights to larger studies than fixed effect analysis.

\section{Conclusions}

Considering all the facts, this was the first comprehensive systematic review and meta-analysis of the effect of probiotic dairy products on respiratory tract infections, by including 22 clinical trials with 33 datasets. Our analysis indicated protection effect of FPDPs against RTIs in all age subgroup.

\section{Abbreviations}

PFDP: Probiotic fermented dairy products; RTIs: Respiratory tract infections; RCTs: Randomized controlled trials; URTIs: Upper respiratory tract infections; LRTIs: Lower respiratory tract infections; RR: Relative risks; Cl: Confidence intervals; IL-12: Interleukin-12; IL-10: Interleukin-10; AMPs: Antimicrobial peptides; IgA: Immunoglobulin A; IgG: Immunoglobulin G; NK: Natural killer 


\section{Supplementary Information}

The online version contains supplementary material available at https://doi. org/10.1186/s12937-021-00718-0.

Additional file 1: Supplemental file 1. Search strategy of the study. Supplemental Table 1. Sensitivity analysis by removing one study at a time and reanalyzing other studies

\section{Acknowledgements}

Not Applicable.

\section{Authors' contributions}

SA \& PJ, MD, and AD contributed to conceptualization, Data curation, Forma analysis, Investigation, Methodology, Project administration, Validation, and Visualization. KR and BR contributed to writing the manuscript. SA contributed to Data analysis, Supervision, Validation, Writing - review \& editing. The author(s) read and approved the final manuscript.

\section{Funding}

None.

\section{Availability of data and materials}

The datasets used and/or analysed during the current study are available from the corresponding author on reasonable request.

\section{Declarations}

Ethics approval and consent to participate

Not applicable.

\section{Consent for publication}

Not applicable.

\section{Competing interests}

The authors declare that they have no competing interests.

\section{Author details}

'Department of Food Sciences and Technology, Faculty of Nutrition and Food Technology, National Nutrition and Food Technology Research Institute, Shahid Beheshti University of Medical Sciences, Tehran, Iran. ${ }^{2}$ Department of Hematology and Blood Banking, School of Medicine, Tarbiat Modares University (TMU), Tehran, Iran. ${ }^{3}$ Department of Clinical Nutrition and Dietetics, Faculty of Nutrition Sciences and Food Technology, National Nutrition and Food Technology Research Institute, Shahid Beheshti University of Medical Sciences, Tehran, Iran. ${ }^{4}$ Nutrition Research Center, Department of Community Nutrition, Faculty of Nutrition and Food Science, Tabriz University of Medical Sciences, Tabriz, Iran. ${ }^{5}$ Student Research Committee, Tabriz University of Medical Sciences, Tabriz, Iran. ${ }^{6}$ Department of Clinical Nutrition, School of Nutritional Sciences and Dietetics, Tehran University of Medical Sciences (TUMS), Tehran, Iran.

\section{Received: 6 December 2020 Accepted: 15 June 2021}

\section{Published online: 28 June 2021}

\section{References}

1. Organization WH. World health report 2004 statistical annex. Geneva: WHO; 2004.

2. Mulholland K. Global burden of acute respiratory infections in children: implications for interventions. Pediatr Pulmonol. 2003;36(6):469-74.

3. Heikkinen T, Järvinen A. The common cold. The Lancet. 2003;361(9351):519

4. Jain S. Epidemiology of viral pneumonia. Clin Chest Med. 2017;38(1):1-9.

5. Mouton CP, Bazaldua OV, Pierce B, Espino DV. Common infections in older adults. Am Family Phys. 2001;63(2):257.

6. Chonmaitree T, Revai K, Grady JJ, Clos A, Patel JA, Nair S, et al. Viral upper respiratory tract infection and otitis media complication in young children. Clin Infect Dis. 2008;46(6):815-23.

7. von Linstow ML, Holst KK, Larsen K, Koch A, Andersen PK, Høgh B. Acute respiratory symptoms and general illness during the first year of life: $A$ population-based birth cohort study. Pediatr Pulmonol. 2008;43(6):584-93.
8. Lehtoranta L, Latvala S, Lehtinen MJ. Role of Probiotics in Stimulating the Immune System in Viral Respiratory Tract Infections: a Narrative Review. Nutrients. 2020;12(10):3163.

9. Ebringer L, Ferenčík M, Krajčovič J. Beneficial health effects of milk and fermented dairy products. Folia Microbiol. 2008;53(5):378-94.

10. Kekkonen RA, Vasankari TJ, Vuorimaa T, Haahtela T, Julkunen I, Korpela R. The effect of probiotics on respiratory infections and gastrointestinal symptoms during training in marathon runners. Int I Sport Nutr Exerc Metab. 2007;17(4):352-63.

11. Wannmacher L. Evidências sobre uso de antibacterianos nas infecções respiratórias altas. Organização Pan-Americana da Saúde/Organização Mundial da Saúde-Brasil. Uso racional de medicamentos. 2006;4(1).

12. Rijkers GT, Bengmark S, Enck P, Haller D, Herz U, Kalliomaki M, et al. Guidance for substantiating the evidence for beneficial effects of probiotics: current status and recommendations for future research. J Nutr. 2010;140(3): 671S-6S.

13. Hotel AC, Cordoba A. Health and nutritional properties of probiotics in food including powder milk with live lactic acid bacteria. Prevention. 2001;5(1):110.

14. Merenstein D, Murphy M, Fokar A, Hernandez RK, Park H, Nsouli H, et al. Use of a fermented dairy probiotic drink containing Lactobacillus casei (DN-114 001) to decrease the rate of illness in kids: the DRINK study A patientoriented, double-blind, cluster-randomized, placebo-controlled, clinical trial. Eur J Clin Nutr. 2010;64(7):669-77.

15. Brunser O, Araya M, Espinoza J, Guesry P, Secretin M, Pacheco I. Effect of an Acidified Milk on Diarrhoea and the Carrier State in Infants of Low SocioEconomic Stratum. Acta Paediatr. 1989;78(2):259-64.

16. Campeotto F, Suau A, Kapel N, Magne F, Viallon V, Ferraris L, et al. A fermented formula in pre-term infants: clinical tolerance, gut microbiota, down-regulation of faecal calprotectin and up-regulation of faecal secretory IgA. Br J Nutr. 2011;105(12):1843-51.

17. Nagata S, Asahara T, Ohta T, Yamada T, Kondo S, Bian L, et al. Effect of the continuous intake of probiotic-fermented milk containing Lactobacillus casei strain Shirota on fever in a mass outbreak of norovirus gastroenteritis and the faecal microflora in a health service facility for the aged. Br I Nutr. 2011;106(4):549-56.

18. Thibault $\mathrm{H}$, Aubert-Jacquin $\mathrm{C}$, Goulet $\mathrm{O}$. Effects of long-term consumption of a fermented infant formula (with Bifidobacterium breve c50 and Streptococcus thermophilus 065) on acute diarrhea in healthy infants. J Pediatr Gastroenterol Nutr. 2004;39(2):147-52.

19. Mullié C, Yazourh A, Thibault H, Odou M-F, Singer E, Kalach N, et al. Increased poliovirus-specific intestinal antibody response coincides with promotion of Bifidobacterium longum-infantis and Bifidobacterium breve in infants: a randomized, double-blind, placebo-controlled trial. Pediatr Res, 2004;56(5):791-5.

20. Nomoto K. Prevention of infections by probiotics. J Biosci Bioengineer. 2005; 100(6):583-92

21. Alvarez-Olmos Ml, Oberhelman RA. Probiotic agents and infectious diseases: a modern perspective on a traditional therapy. Clin Infect Dis. 2001;32(11): 1567-76.

22. Jafar-Abadi MA, Dehghani A, Khalili L, Barzegar A, Mesrizad M, Hassanalilou T. A Meta-analysis of Randomized Controlled Trials of the Effect of Probi-otic Food or Supplement on Glycemic Response and Body Mass Index in Patients with Type 2 Diabetes, Updating the Evidence. Curr Diabetes Rev. 2020;17(3):356-364.

23. Panesar PS, Kaur G, Panesar R, Bera MB. Synbiotics: potential dietary supplements in functional foods. Berkshire: IFIS; 2009.

24. King S, Glanville J, Sanders ME, Fitzgerald A, Varley D. Effectiveness of probiotics on the duration of illness in healthy children and adults who develop common acute respiratory infectious conditions: a systematic review and meta-analysis. Br J Nutr. 2014;112(1):41-54.

25. Amaral MA, Guedes GHBF, Epifanio M, Wagner MB, Jones MH, Mattiello R. Network meta-analysis of probiotics to prevent respiratory infections in children and adolescents. Pediatr Pulmonol. 2017;52(6):833-43.

26. Agustina R, Kok FJ, Van De Rest O, Fahmida U, Firmansyah A, Lukito W, et al. Randomized trial of probiotics and calcium on diarrhea and respiratory tract infections in Indonesian children. Pediatrics. 2012;129(5):e1155-e64.

27. Corsello G, Carta M, Marinello R, Picca M, De Marco G, Micillo M, et al. Preventive effect of cow's milk fermented with Lactobacillus paracasei CBA L74 on common infectious diseases in children: A multicenter randomized controlled trial. Nutrients. 2017;9(7):669. 
28. Fujita R, limuro S, Shinozaki T, Sakamaki K, Uemura $Y$, Takeuchi A, et al. Decreased duration of acute upper respiratory tract infections with daily intake of fermented milk: a multicenter, double-blinded, randomized comparative study in users of day care facilities for the elderly population. Am J Infect Control. 2013;41(12):1231-5.

29. Guillemard E, Tanguy J, Flavigny AL, de la Motte S, Schrezenmeir J. Effects of consumption of a fermented dairy product containing the probiotic Lactobacillus casei DN-114 001 on common respiratory and gastrointestinal infections in shift workers in a randomized controlled trial. J Am Coll Nutr. 2010;29(5):455-68.

30. Guo C, Lei M, Wang Y, Hua L, Xue S, Yu D, et al. Oral Administration of Probiotic Lactobacillus Casei Shirota Decreases Pneumonia and Increases Pulmonary Functions after Single Rib Fracture: A Randomized Double-Blind, Placebo-Controlled Clinical Trial. J Food Sci. 2018;83(8):2222-6.

31. Hatakka K, Savilahti E, Pönkä A, Meurman JH, Poussa T, Näse L, et al. Effect of long term consumption of probiotic milk on infections in children attending day care centres: double blind, randomised trial. BMJ. 2001; 322(7298):1327.

32. Hojsak I, Abdović S, Szajewska H, Milošević M, Krznarić Ž, Kolaček S. Lactobacillus GG in the prevention of nosocomial gastrointestinal and respiratory tract infections. Pediatrics. 2010;125(5):e1171-e7.

33. Hojsak I, Snovak N, Abdović S, Szajewska H, Mišak Z, Kolaček S. Lactobacillus $\mathrm{GG}$ in the prevention of gastrointestinal and respiratory tract infections in children who attend day care centers: a randomized, double-blind, placebocontrolled trial. Clin Nutr. 2010;29(3):312-6.

34. Jespersen L, Tarnow I, Eskesen D, Morberg CM, Michelsen B, Bügel S, et al. Effect of Lactobacillus paracasei subsp. paracasei, L. casei 431 on immune response to influenza vaccination and upper respiratory tract infections in healthy adult volunteers: a randomized, double-blind, placebo-controlled, parallel-group study. Am J Clin Nutr. 2015;101(6):1188-96.

35. Kinoshita T, Maruyama K, Suyama K, Nishijima M, Akamatsu K, Jogamoto A et al. The effects of OLL1073R-1 yogurt intake on influenza incidence and immunological markers among women healthcare workers: a randomized controlled trial. Food Funct. 2019;10(12):8129-36.

36. Kumpu M, Kekkonen R, Kautiainen $H$, Järvenpää S, Kristo A, Huovinen $P$, et al. Milk containing probiotic Lactobacillus rhamnosus GG and respiratory illness in children: a randomized, double-blind, placebo-controlled trial. Eur J Clin Nutr. 2012;66(9):1020-3.

37. Mai TT, Thu PT, Hang HT, Trang TT, Yui S, Shigehisa A, Tien VT, Dung TV, Nga PB, Hung NT. Efficacy of probiotics on digestive disorders and acute respiratory infections: a controlled clinical trial in young Vietnamese children. Eur J Clin Nutr. 2021;75(3):513-520.

38. Makino S, Ikegami S, Kume A, Horiuchi H, Sasaki H, Orii N. Reducing the risk of infection in the elderly by dietary intake of yoghurt fermented with Lactobacillus delbrueckii ssp. bulgaricus OLL1073R-1. Br J Nutr. 2010;104(7): 998-1006.

39. Meng H, Lee $Y, B a Z$, Peng J, Lin J, Boyer AS, et al. Consumption of Bifidobacterium animalis subsp. lactis BB-12 impacts upper respiratory tract infection and the function of NK and T cells in healthy adults. Mol Nutr Food Res. 2016;60(5):1161-71.

40. Prodeus A, Niborski V, Schrezenmeir J, Gorelov A, Shcherbina A, Rumyantsev A. Fermented milk consumption and common infections in children attending day-care centers: a randomized trial. J Pediatr Gastroenterol Nutr. 2016;63(5):534

41. Pu F, Guo Y, Li M, Zhu H, Wang S, Shen X, et al. Yogurt supplemented with probiotics can protect the healthy elderly from respiratory infections: a randomized controlled open-label trial. Clin Interv Aging. 2017;12:1223.

42. Rongrungruang Y, Krajangwittaya D, Pholtawornkulchai K, Tiengrim S, Thamlikitkul V. Randomized controlled study of probiotics containing Lactobacillus casei (Shirota strain) for prevention of ventilator-associated pneumonia. J Med Assoc Thai. 2015;98(3):253-9.

43. Sazawal S, Dhingra U, Hiremath G, Sarkar A, Dhingra P, Dutta A, et al. Prebiotic and probiotic fortified milk in prevention of morbidities among children: community-based, randomized, double-blind, controlled trial. Plos one. 2010;5(8):e12164.

44. Shida K, Sato T, lizuka R, Hoshi R, Watanabe O, Igarashi T, et al. Daily intake of fermented milk with Lactobacillus casei strain Shirota reduces the incidence and duration of upper respiratory tract infections in healthy middle-aged office workers. Eur J Nutr. 2017;56(1):45-53.

45. Van Puyenbroeck K, Hens N, Coenen S, Michiels B, Beunckens C, Molenberghs $\mathrm{G}$, et al. Efficacy of daily intake of Lactobacillus casei Shirota on respiratory symptoms and influenza vaccination immune response: a randomized, double-blind, placebo-controlled trial in healthy elderly nursing home residents. Am J Clin Nutr. 2012;95(5):1165-71.

46. Guillemard E, Tondu F, Lacoin F, Schrezenmeir J. Consumption of a fermented dairy product containing the probiotic Lactobacillus casei DN114001 reduces the duration of respiratory infections in the elderly in a randomised controlled trial. Br J Nutr. 2010;103(1):58-68.

47. Rijkers GT, Bengmark S, Enck P, Haller D, Herz U, Kalliomaki M, Kudo S, Lenoir-Wijnkoop I, Mercenier A, Myllyluoma E, Rabot S. Guidance for substantiating the evidence for beneficial effects of probiotics: current status and recommendations for future research. J Nutr. 2010;140(3):671S-6S.

48. Pineiro M, Stanton CJTJon. Probiotic bacteria: legislative framework —requirements to evidence basis. J Nutr. 2007;137(3):850S-3S.

49. Nanno M, Kato I, Kobayashi T, Shida KJljoi, pharmacology. Biological effects of probiotics: what impact does Lactobacillus casei shirota have on us? Int J Immunopathol Pharmacol. 2011;24(1 Suppl):45S-50S.

50. Dong H, Rowland I, Yaqoob PJBJoN. Comparative effects of six probiotic strains on immune function in vitro. Br J Nutr. 2012;108(3):459-70.

51. Curto AL, Pitino I, Mandalari G, Dainty JR, Faulks RM, Wickham MSJJFm. Survival of probiotic lactobacilli in the upper gastrointestinal tract using an in vitro gastric model of digestion. Food Microbiol. 2011;28(7):1359-66.

52. Zagato E, Mileti E, Massimiliano L, Fasano F, Budelli A, Penna G, et al. Lactobacillus paracasei CBA L74 metabolic products and fermented milk for infant formula have anti-inflammatory activity on dendritic cells in vitro and protective effects against colitis and an enteric pathogen in vivo. PLoS One. 2014;9(2):e87615.

53. Chung FJMoi. Anti-inflammatory cytokines in asthma and allergy: interleukin-10, interleukin-12, interferon-y. Mediators Inflamm. 2001;10(2):5159

54. Diamond G, Beckloff N, Weinberg A, Kisich KOJCpd. The roles of antimicrobial peptides in innate host defense. Curr Pharm Des. 2009;15(21): 2377-92.

55. Ganz TJTJoci. Antimicrobial polypeptides in host defense of the respiratory tract. J Clin Invest. 2002;109(6):693-7.

56. Kato LM, Kawamoto S, Maruya M, Fagarasan SJI, biology c. Gut TFH and IgA: key players for regulation of bacterial communities and immune homeostasis. Immunol Cell Biol. 2014;92(1):49-56.

57. Trebichavský I, Šplíchal I. Probiotics manipulate host cytokine response and induce antimicrobial peptides. Folia Microbiol. 2006;51(5):507-10.

58. Alberda C, Gramlich L, Meddings J, Field C, McCargar L, Kutsogiannis D, et al. Effects of probiotic therapy in critically ill patients: a randomized, double-blind, placebo-controlled trial. Am J Clin Nutr. 2007:85(3):816-23.

59. Reale M, Boscolo P, Bellante V, Tarantelli C, Di Nicola M, Forcella L, et al. Daily intake of Lactobacillus casei Shirota increases natural killer cell activity in smokers. Br J Nutr. 2012;108(2):308-14.

60. Dong H, Rowland I, Tuohy K, Thomas L, Yaqoob PJC, Immunology E. Selective effects of Lactobacillus casei Shirota on T cell activation, natural killer cell activity and cytokine production. Clin Exp Immunol. 2010;161(2): $378-88$.

\section{Publisher's Note}

Springer Nature remains neutral with regard to jurisdictional claims in published maps and institutional affiliations.

Ready to submit your research? Choose BMC and benefit from:

- fast, convenient online submission

- thorough peer review by experienced researchers in your field

- rapid publication on acceptance

- support for research data, including large and complex data types

- gold Open Access which fosters wider collaboration and increased citations

- maximum visibility for your research: over $100 \mathrm{M}$ website views per year

At $\mathrm{BMC}$, research is always in progress.

Learn more biomedcentral.com/submission 